\title{
PENGARUH TRAKSI MANUAL CERVICAL TERHADAP NYERI LEHER AKIBAT DISC MIGRATION
}

\author{
Safrin Arifin ${ }^{1}$ \\ ' Tenaga Pengajar Program Studi Fisioterapi Universitas Indonesia
}

\begin{abstract}
Abstrak - Penelitian bertujuan untuk mengetahui pengaruh traksi manual cervical pada nyeri leher akibat disc migration. Penelitian dilakukan dengan mengambil sampel pasien rawat jalan di Rumah Sakit Pondok Indah. Pelaksanaan penelitian dimulai dari bulan Mei sampai dengan bulan Agustus 2013. Metode penelitian bersifat Quasi eksperimental untuk mengetahui efek suatu intervensi atau perlakuan pada objek penelitian, Dengan kata lain ada intervensi terhadap suatu variabel dan ada monitoring perubahan efek. Pengolahan dan analisis data dilakukan dengan uji Wilcoxon dan uji Mann-Whytney menggunakan program Statistical Program for Social Science (SPSS 10.0) untuk melihat efek perlakuan terhadap objek penelitian. Penelitian menyimpulkan bahwa traksi manual cervical berpengaruh pada penurunan intensitas nyeri leher akibat disc migration. Dengan demikian teknik ini dapat digunakan sebagai salah satu metode fisioterapi dalam pengobatan disc migration.

Berdasarkan kesimpulan di atas diharapkan agar fisioterapis khususnya yang bertugas di Rumah Sakit atau Klinik untuk selalu berusaha membuka wawasan berfikir dalam mempelajari dan mengembangkan metode - metode pengobatan yang efektif dan efisien seperti penerapan traksi manual cervical pada nyeri leher akibat disc migration.
\end{abstract}

Kata Kunci: Traksi Manual, Nyeri Leher, Disc Migration

\section{PENDAHULUAN}

\section{Latar Belakang}

Dalam praktek fisioterapi sering dijumpai keluhan nyeri leher yang sangat beragam, dimana berdasarkan penelitian kasus nyeri leher merupakan kasus muskuloskeletal terbanyak setelah kasus nyeri pinggang bawah dan kasus ini sulit ditangani secara tuntas karena susunan anatomis dan fungsi yang sangat kompleks, serta mempunyai resiko yang sangat tinggi mengingat besar pengaruhnya terhadap gerak dan fungsi dasar tubuh, mempengaruhi sistem saraf kuadran atas serta berpengaruh terhadap pembuluh darah ke otak (Sugianto.,2002). Nyeri leher itu sendiri merupakan suatu gejala yang berasal dari patologi jaringan spesifik tertentu atau patologi tertentu. Nyeri yang terjadi tersebut disebabkan oleh beberapa faktor seperti kesalahan sikap, spondilosis, spondilolistesis, iritasi radiks, whiplash injuri, vertebro basillar insuficienci, penguncian sendi facet, disc migration dan Iain-lain.

Karena penyebab yang beragam, maka ciri nyerinya pun beragam, salah satu penyebabnya adalah disc migration. Keadaan ini banyak disebabkan oleh kesalahan posisi dalam waktu yang cukup lama sehingga terjadi pembebanan yang tidak simetris pada intradiskal, seperti bekerja dengan posisi duduk sambil menunduk 
atau posisi tidur terlentang dengan bantal yang tinggi dalam waktu yang lama.

Harms dan Ringdahl meneliti nyeri leher akibat dari perubahan posisi kepala menunduk dalam waktu yang lama, dimana 10 subjek tanpa gejala mempertahankan posisi tersebut dan diperoleh hasil nyeri terjadi setelah 16-57 menit (Mc. KenzieR.A, 1992).

Disc migration dapat menyebabkan nyeri hebat pada leher karena dengan berpindahnya discus akibat pembebanan yang tidak simetris tersebut dapat mengiritasi jaringan disekitarnya seperti ligamen longitudinal posterior yang kaya dengan serabut saraf tipe IV, sendi facet, kapsul sendi, membran sinovial, duramater dan lain - lain ((Moore et al., 2009).

Banyak teknik dan metoda fisioterapi yang dapat diaplikasikan dalam menangani nyeri yang terjadi akibat disc migration, seperti penggunaan alat - alat elektro terapi (MWD, TENS, IF, US), massage, terapi latihan, dan teknik mobilisasi lainnya. Salah satu modalitas fisioterapi yang dianggap paling tepat adalah traksi manual cervical.

Berdasarkan latar belakang tersebut, penulis tertarik untuk mengangkat topik di atas dalam bentuk penelitian dengan judul "Pengaruh Traksi Manual Cervical Terhadap Nyeri Leher Akibat Disc Migration".

\section{Kerangka Berfikir}

Disc migration adalah kondisi dimana nukleus pulposus berpindah tempat akibat dari beban asimetris, perpindahan tersebut biasanya mendorong annulus fibrosus sehingga menonjol ke arah depan beban tersebut, misalnya pada posisi fleksi yang lama maka nukleus pulposus akan terdorong ke arah belakang, akibatnya dapat menekan dan mengiritasi ligamentum longitudinal posterior yang banyak mengandung serabut saraf afferen tipe IV. Begitu juga halnya dengan pengaruh mekanikal pada persendian terutama pada uncovertebral joint (joint of Von Lushka) dan facet joint, apabila terjadi gerakan rotasi homolateral dan lateral fleksi kontralateral maka facet pada sisi kontralateral tetap dan facet pada sisi homolateral terjadi pembukaan yang berarti terjadi pergeseran nukleus pulposus pada sisi homolateral ke arah posterolateral discus intervertebralis yang mengandung annulus fibrosus yang tipis, sehingga dengan mudah terjadi penojolan discus yang dapat mengiritasi komponen - komponen sendi peka nyeri seperti ligamen.Bergesernya nukleus pulposus dari lokasi asal akibat pembebanan yang asimetrik sangat lambat. Sedangkan untuk mempercepat kembali keposisi semula diperlukan gerakan yang berlawanan atau dengan traksi.MWD dengan sedative effect dapat menurunkan nyeri dan spasme otot melalui stimulasi sekunder pada afferent muscle spindle nerve ending dan organ tendon golgi. Efek lain adalah meningkatkan metabolisme, sehingga dapat menurunkan nyeri akibat iskemia jaringan. TENS dapat merangsang pelepasan endorphinedependent system dan serotonin-dependent system oleh tubuh. Dengan demikian dapat menghambat timbulnya nyeri akibat iritasi jaringan peka rangsang seperti ligamen dan secara tidak langsung menurunkan spasme otototot tengkuk akibat disc migration. 
Berdasarkan pernyataan diatas ditinjau dari segi patologi struktur jaringan spesifik, biomekanik dan penyebab nyeri leher akibat disc migration maka modalitas fisioterapi yang paling cocok untuk diterapkan adalah dengan traksi manual cervical karena dapat mengurangi nyeri secara langsung dengan mengembalikan posisi discus ke tempat semula serta merilekasikan jaringan otot yang mengalami spasme.

\section{MWD}

\section{TENS}
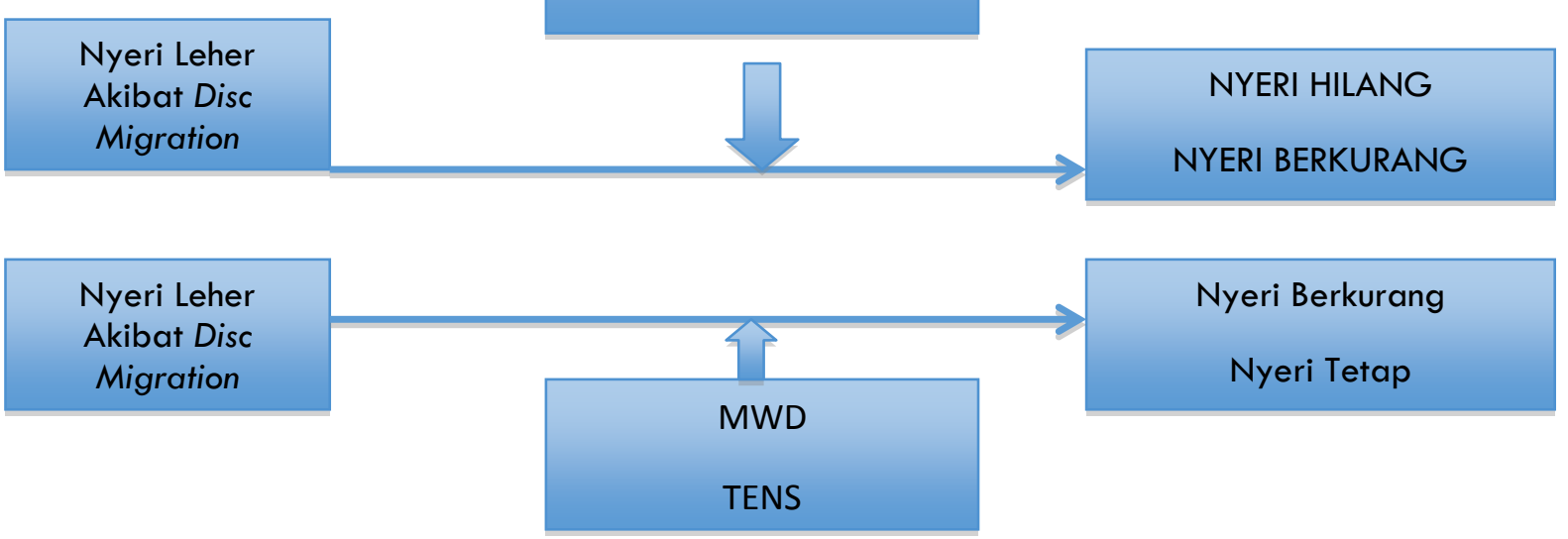

\section{Metode Penelitian}

Penelitian ini bersifat Quasi Eksperimen untuk mempelajari fenomena korelasi sebab akibat dengan memberikan perlakuan pada obyek penelitian. Dengan kata lain ada perlakuan berupa penerapan modalitas traksi manual cervical terhadap kondisi disc migration dan monitoring perubahan efek berupa penuruan rasa nyeri sebagai dampak perlakuan yang diberikan.

Pada penelitian ini subjek di bagi menjadi dua kelompok, yakni kelompok perlakuan dan kelompok control.

a. Kelompok Perlakuan

\begin{tabular}{|l|l|l|}
\hline \multicolumn{1}{|c|}{ Awal } & \multicolumn{1}{|c|}{ Intervensi } & \multicolumn{1}{c|}{ akhir } \\
\hline Nyeri akibat & MWD & Nyeri \\
disc & TENS & berkurang \\
migration & TRAKSI & Nyeri hilang \\
& MANUAL & \\
& CERVICAL & \\
\hline
\end{tabular}

\section{b. Kelompok Kontrol}

\begin{tabular}{|l|l|l|}
\hline \multicolumn{1}{|c|}{ Awal } & \multicolumn{1}{c|}{ Intervensi } & \multicolumn{1}{c|}{ akhir } \\
\hline $\begin{array}{l}\text { Nyeri akibat } \\
\text { disc } \\
\text { migration }\end{array}$ & MWD & $\begin{array}{l}\text { Nyeri tetap } \\
\text { Tyeri } \\
\text { berkurang }\end{array}$ \\
\hline
\end{tabular}

\section{Teknik Pengambilan Sampel}

Pada penelitian ini, pegambilan sampel dilakukan dengan teknik purposive sampling. Teknik pengambilan sampel ini dilakukan berdasarkan pertimbangan agar mendapatkan gambaran hasil pengujian suatu teknik perlakuan menggunakan modalitas traksi manual cervical dengan memilih sampel yang telah memenuhi kriteria yang telah ditetapkan.

Sampel dalam penelitian ini berjumlah 30 orang wanita dan laki - laki antara umur 25 - 46 tahun yagn dibagi dalam dua kelompok, 15 orang kelompok perlakuan dan 15 orang kelompok kontrol. 


\section{Instrumen Penelitian}

Instrumen penelitian yang digunakan dalam penelitian ini adalah ;

1. Visual Analog Scale(VAS)

Visual Analog Scale (VAS) adalah suatu pengukuran yang digunakan untuk menilai intensitas nyeri. VAS lebih sensitive untuk melihat perubahan pada nyeri. Dalam aplikasinya VAS menggunakan garis horizontal sepanjang $10 \mathrm{~cm}$, dimana satu ujungnya diberi tanda yang berarti “ tidak ada nyeri” sedangkan yang lainnya diberi tanda yang berarti "Nyeri tidak tertahankan”. Pasien memberi tanda disepanjang garis tersebut daerah yang paling sesuai dengan intensitas nyeri yang dirasakan, kemudian pasien diberikan intervensi sebanyak 3 kali dengan menggunakan MWD, TENS dan Traksi Manual Cervical dengan MWD dan TENS.

\section{Tidak nyeri}

Nyeri Tidak Tertahankan

2. Lembaran Kuisioner
Lembaran kuisioner ini digunakan untuk mengidentifikasi mereka yang menderita nyeri akibat disc migration

\section{ANALISIS DAN PEMBAHASAN}

Dalam penelitian ini sampel berasal dari pasien rawat jalan di Rumah Sakit Pondok Indah yang secara keseluruhan berjumlah kurang lebih 39 orang. Sampel diperoleh melalui hasil lembaran quisioner yang dibagikan sebelum penelitian kemudian diobservasi kembali untuk menentukan jumlah, jenis kelamin, dan usia. Secara keseluruhan sampel berjumlah 30 orang dengan jenis kelamin laki - laki dan perempuan dan berusia antara 20 - 50, dengan 15 orang kelompok perlakuan dan 15 orang kelompok kontrol. Setelah itu sampel dibagi dalam dua kelompok yang diberikan perlakuan berbeda yakni kelompok perlakuan dan kelompok kontrol dengan jumlah yang sama seperti pada tabel berikut:

Tabel 1.

Distribusi sampel menurut usia

\begin{tabular}{lccc}
\hline Usia & Kelompok perlakuan & Kelompok Kontrol & Total \\
\hline $20-24$ & $\mathbf{4}$ & $\mathbf{3}$ & $\mathbf{7}$ \\
$25-29$ & $\mathbf{3}$ & $\mathbf{3}$ & $\mathbf{6}$ \\
$30-34$ & $\mathbf{2}$ & $\mathbf{2}$ & $\mathbf{4}$ \\
$35-39$ & $\mathbf{2}$ & $\mathbf{2}$ & $\mathbf{4}$ \\
$40-44$ & $\mathbf{1}$ & $\mathbf{2}$ & $\mathbf{3}$ \\
$45-49$ & $\mathbf{2}$ & $\mathbf{2}$ & $\mathbf{4}$ \\
$>50$ & $\mathbf{1}$ & $\mathbf{1}$ & $\mathbf{2}$ \\
\hline Jumlah & $\mathbf{1 5}$ & $\mathbf{1 5}$ & $\mathbf{3 0}$ \\
\hline
\end{tabular}




\section{Profil Nyeri Awal dan Akhir Penelitian}

Secara keseluruhan sampel berjumlah 30 orang dengan jenis kelamin laki-laki dan perempuan dengan umur di atas 20 Tahua Kemudian sampel dibagi menjadi dua kelompok yakni kelompok perlakuan 15 orang dan kelompok kontol 15 orang.

Tabel 2.

Perbandingan data pada Visual Analogue Scale

(VAS) sebelum perlakuan dan sebelum kontrol.

\begin{tabular}{|c|c|c|}
\hline \multirow{2}{*}{ No } & \multicolumn{2}{|c|}{ S e b e l u m } \\
\hline & Perlakuan & Kontrol \\
\hline 1 & 70 & 65 \\
\hline 2 & 65 & 60 \\
\hline 3 & 60 & 70 \\
\hline 4 & 58 & 62 \\
\hline 5 & 68 & 63 \\
\hline 6 & 60 & 60 \\
\hline 7 & 50 & 68 \\
\hline 8 & 51 & 60 \\
\hline 9 & 55 & 59 \\
\hline 10 & 50 & 55 \\
\hline 11 & 64 & 40 \\
\hline 12 & 62 & 58 \\
\hline 13 & 65 & 62 \\
\hline 14 & 67 & 65 \\
\hline 15 & 70 & 62 \\
\hline Mean & 61,00 & 60,60 \\
\hline SD & 6,96 & 6,86 \\
\hline
\end{tabular}

Sebelum dilakukan intervensi dengan traksi manual cervical, dilakukan pengukuran nyeri terlebih dahulu pada kelompok perlakuan dan kelompok kontrol untuk menentukan tingkat nyerinya. Kemudian setelah dilakukan intervensi dengan traksi manual cervical, dilakukan kembali pengukuran nyeri untuk melihat tingkat keberhasilan dari intervensi yang diberikan.

Dengan uji Mann - Whitney, nilai Visual Analogue Scale (VAS) sebelum intervensi kelompok perlakuan dan kelompok kontrol tjdak mempunyai perbedaan yang bermakna dengan $p=0,870$, dan $\%=0,188$. Sehingga $\mathrm{P}>005$.

Tabel 3.

Nilai pengukuran "Visual Analogue Scale" kelompok perlakuan sebelum dan sesudah intervensi

\begin{tabular}{|c|c|c|c|}
\hline \multirow{2}{*}{ Subjek } & \multicolumn{3}{|c|}{ Perlakuan } \\
\cline { 2 - 4 } & Sebelum & Sesudah & Selisih \\
\hline 1 & 70 & 10 & 60 \\
\hline 2 & 65 & 5 & 60 \\
\hline 3 & 60 & 15 & 45 \\
\hline 4 & 58 & 8 & 50 \\
\hline 5 & 68 & 0 & 68 \\
\hline 6 & 60 & 20 & 40 \\
\hline 7 & 50 & 5 & 45 \\
\hline 8 & 51 & 5 & 46 \\
\hline 9 & 55 & 8 & 47 \\
\hline 10 & 50 & 20 & 30 \\
\hline 11 & 64 & 10 & 54 \\
\hline 12 & 62 & 15 & 47 \\
\hline 13 & 65 & 25 & 40 \\
\hline 14 & 67 & 5 & 62 \\
\hline & & & \\
\hline 19 & 50 & 5 & 5 \\
\hline
\end{tabular}




\begin{tabular}{|c|c|c|c|}
\hline \multirow{2}{*}{ Subjek } & \multicolumn{3}{|c|}{ Perlakuan } \\
\cline { 2 - 4 } & Sebelum & Sesudah & Selisih \\
\hline 15 & 70 & 0 & 70 \\
\hline Mean & 61,00 & 10,07 & 50,93 \\
\hline SD & 6,96 & 7,47 & 11,20 \\
\hline
\end{tabular}

Dengan uji Wilcoxon nilai Visual Analogue Scale kelompok perlakuan mengalami perubahan secara bermakna ( $\mathrm{P}=0,001, \% 2=3,411)$ dimana $\mathrm{P}<0,05$. dibanding sebelum perlakuan.

Tabel 4 .

Nilai Pengukuran Visual Analogue Scale Kelompok Kontrol sebelum dan sesudah intervensi.

\begin{tabular}{|c|c|c|c|}
\hline \multirow{2}{*}{ Subjek } & \multicolumn{3}{|c|}{ Kontrol } \\
\cline { 2 - 4 } & Sebelum & Sesudah & Selisih \\
\hline 1 & 65 & 65 & 0 \\
\hline 2 & 60 & 60 & 0 \\
\hline 3 & 70 & 68 & 2 \\
\hline 4 & 62 & 61 & 1 \\
\hline 5 & 63 & 62 & 1 \\
\hline 6 & 60 & 60 & 0 \\
\hline 7 & 68 & 66 & 2 \\
\hline 8 & 60 & 60 & 0 \\
\hline 9 & 59 & 59 & 0 \\
\hline 10 & 55 & 53 & 2 \\
\hline 11 & 40 & 40 & 0 \\
\hline 12 & 58 & 57 & 1 \\
\hline 13 & 62 & 60 & 2 \\
\hline 14 & 65 & 65 & 0 \\
\hline 15 & 62 & 62 & 0 \\
\hline Mean & 60,60 & 59,87 & 0,73 \\
\hline SD & 6,86 & 6,64 & 0,88 \\
\hline
\end{tabular}

Dengan uji Wilcoxon nilai Visual Analogue Scale kelompok kontrol mengalami perubahan secara bermakna $(p=0,015, \% 2=2,428)$ dimana $\mathrm{P}<0,05$.

Dari hasil penelitian ini dapat disimpulkan bahwa teknik traksi manual cervical berpengaruh secara signifikan terhadap penurunan nyeri leher akibat disc migration

\section{KESIMPULAN}

Disc migration adalah suatu kondisi yang disebabkan oleh pembebanan yang asimetrik yang berlangsung lama, seperti bekerja dengan posisi duduk sambil membungkuk dan tidur dengan memakai bantal yang tinggi, sehingga menyebabkan berpindahnya nukleus pulposus ke bagian depan beban yang diterima, apabila hal ini berlangsung lama dapat menyebabkan penonjolan discus ke belakang sehingga dapat secara langsung mengiritasi ligamen longitudinal posterior yang peka nyeri. Nyeri yang timbul akibat disc migration menyebabkan aktivasi serabut saraf sensoris tipe A5 dan C yang ada di sekitar ligamen longitudinal posterior, kemudian impuls nyeri berjalan ke atas melalui traktus spinothalamikus lateral ke nukleus posteromedial ventral dan posterolateral dari thalamus. Dari sini impuls diteruskan ke girus post sentral dari korteks serebri dan terjadi pelepasan zat $\mathrm{P}$ yang menyebabkan timbulnya nyeri (Heru P. Kuntono,2000).

Hasil yang didapat dari penelitian ini mendukung pendapat bahwa traksi manual cervical merupakan metode yang paling tepat untuk modalitas pengurangan nyeri akibat disc migration, sebagaimana telah di gambarkan oleh 
kramer. Pada penelitian ini memenuhi angka statistik yang ditujukkan pada tabel 3. Dari 15 sampel pada kelompok perlakuan didapatkan adanya penurunan yang bermakna begitupun hal nya dengan 15 sampel dari kelompok kontrol, namun berdasarkan tabel 3 dan 4 serta grafik 1. Menunjukkan perbedaan yang bermakna penurunan nyeri antara kelompok perlakuan dengan kelompok kontrol. Hal ini disebabkan karena penggunaan modalitas traksi manual cervical dapat mempercepat terjadinya penumnan rasa nyeri. Penelitian ini memperkuat penelitian terdahulu oleh Kramer yang mengatakan bahwa bergesernya nukleus pulposus dari lokasi asal akibat pembebanan yang asimetrik sangat lambat, sedangkan untuk mempercepat kembali ke posisi semula diperlukan gerakkan yang berlawanan atau dengan traksi.

Penurunan rasa nyeri dengan menggunakan modalitas traksi manual cervical dengan membebaskan secara langsung penyebab rasa nyeri yakni mereposisi discus yang mengalami penonjolan sehingga iritasi ligamentum longitudinal posterior akibat penekanan oleh discus dapat dibebaskan. Begitu pula hal nya dengan penyebab rasa nyeri lainnya seperti kelainan sendi apophyseal, kelainan ini dapat disebut dengan nyeri hipomobilitas yang disebabkan oleh subluksasi atau derangemen interna pada sendi facet yang memiliki meniscoid dan merusak sinovial sendi sehingga menyebabkan sendi terkuncl Pada keadaan ini traksi manual cervical sangat efektif, tehitama untuk mengoreksi masalah mekanik.

Akibat nyeri yang disebabkan oleh disc migration, maka dapat menyebakan spasme otot, sehingga dengan manipulasi dan traksi manual cervical semuanya memberikan refleks inhibisi pada spasme otot akut atau kronik, hal ini mengikuti teori "gate control" oleh Melzack dan Wall. Adanya penurunan rasa nyeri setelah terapi pada kelompok perlakuan, menunjukan bahwa traksi manual cervical merupakan modalitas yang baik dalam menurunkan nyeri leher akibat disc migration. Pada kelompok kontrol yang terdiri dari 15 sampel yang menggunakan MWD dan TENS didapatkan hasil yang bermakna juga, namun kedua modalitas tersebut belum efektif jika dibandingkan dengan traksi manual cervical, sebagaimana ditunjukkan dalam tabel 3. Akhirnya dapat disimpulkan bahwa traksi manual cervical merupakan terapi yang sederhana dan efektif serta efisien dalam mengurangi nyeri pada leher akibat disc migration.

\section{DAFTAR PUSTAKA}

Cynthia C. Norkin and D. Joice White, Measurement of Joint Motion, A Guide to Goniometry, second edition (Philadelphia, F.A. Davis Company, 1995)

Cyriax James, Orthopaedic Medicine, Volume Two, Treatment by Manipulation, Massage and Injection, Eighth Edition, Bailliere Tindall, London, 1974

Greenman. Philip E, Prinsiples of Manual Medicine, Williams and Wilkins, 1989 
Gersh, Meryl R, TENS for Management of Pain and Sensory Pathology, Electrotherapy in Rehabilitation, (Philadelphia, F.A. Davis Company Ltd, 1992)

Grieve Gregory P, Mobilisation of the Spine, Fifth Edition, Churchill Livingstone, 1991

Harris Siregar, et all, Neuro Fisiologi, Edisi Ketiga, Bagian Ilmu Faal Fakultas Kedokteran UNHAS, Ujungpandang, 1995

Hoppenfeld Stanley, Physical Examination of the Spine and Extremities, Appleton and Lange, New York, 1976

John Low and Ann Reed, Electrotherapy Explained Principles and Practice, Third Edition, Butterworth - Heinemann, 2000

KoninJeffG, Practical Kinesiology for the Physical Therapist Assisstant, SLACK Incorporated, USA, 1999

LGF Giles and KP. Singer, Clinical Anatomy and Management of Cervical Spine, Volume 3, Butteworth - Heinemann, 1998

Maitland G.D, Vertebral Manipulation, Fifth Edition, Bitterworth -Heinemann, 1997

Mc Kenzie. R.A, The Cervical and Thoracic Spine, Mechanical Diagnosis and Therapy, New Zealand. 1992

Moore KL, Dalley AF, Agur AM. Clinically oriented anatomy. 6th ed. Baltimore, MD: Lippincott Williams \& Wilkins; 2009.

Murtagh John and Kenna Clive, Back Pain and Spinal Manipulation, A Practical Guide, Second Edition, Butterworth - Heinemann, 1997

Peat Malcolm, Current Pysical Therapy, BC. Decker Inc, Philadelphia, 1988

Refshauge Kathryn M. and Gass Elizabeth M, Musculoskeletal Physiotherapy Clinical Science and Practice, First Edition, Butterworth -Heinemann, 1995

Seig Kay W. and Adam Sandra P, Illustrated Essentials of Musculoskeletal Anatomy, Third Edition, Megabooks Gainesville, Florida, 1996

Smith Laura K. et all, Brunnstrom's Clinical Kinesiology, Fifth Edition, F.A. Davis Company, Philadelphia, 1996

Sugianto, Manual Terapi Nyeri Leher, Makalah ini disampaikan pada Seminar dan Pelatihan Konsep Mutakhir Nyeri Leher, Bahu dan Pinggang, RSPI, 29 September 2002. 